\title{
The Impact of Fasciation on Maize Inflorescence Architecture
}

\author{
Da Eun Kim ${ }^{1} \cdot$ Jin-hee Jeong ${ }^{2} \cdot$ Yu Mi Kang ${ }^{1}$ - Young-Hoon Park ${ }^{1,4} \cdot$ Yong-Jae Lee $^{1,4} \cdot$ Jum-soon Kang ${ }^{1,4}$. \\ Young-Whan $\mathrm{Choi}^{1,4} \cdot$ Beung-Gu Son ${ }^{1}$ · Sun Tae Kim ${ }^{3,4}$. Dave Jackson ${ }^{5} \cdot$ Byoung II Je
}

Received: 1 November 2021 / Revised: 5 November 2021 / Accepted: 8 November 2021 / Published online: 4 January 2022

(c) The Author(s) 2021

\begin{abstract}
How functional genetics research can be applied to improving crop yields is a timely challenge. One of the most direct methods is to produce larger inflorescences with higher productivity, which should be accompanied by a balance between stem cell proliferation and lateral organ initiation in meristems. Unbalanced proliferation of stem cells causes the fasciated inflorescences, which reflect the abnormal proliferation of meristems, derived from the Latin word 'fascis', meaning 'bundle'. Maize, a model system for grain crops, has shown tremendous yield improvements through the mysterious transformation of the female inflorescence during domestication. In this review, we focus on maize inflorescence architecture and highlight the patterns of fasciation, including recent progress.
\end{abstract}

Keywords Maize $\cdot$ Inflorescence architecture $\cdot$ Fasciation $\cdot$ Crop yields

\section{Introduction}

Maize is one of the most widely cultivated crops in the world, and one of the most important cereal crops along with wheat and rice. Based on the statistics of the Food and Agriculture Organization (FAO), the total production of maize, 1 billion tons, surpasses that of wheat and rice

Da Eun Kim, Jin-hee Jeong and Yu Mi Kang contributed equally to this work.

$\triangle$ Byoung Il Je

bije@pusan.ac.kr

Dave Jackson

jacksond@cshl.edu

1 Department of Horticultural Bioscience, Pusan National University, Miryang 50463, Republic of Korea

2 Division of Applied Life Science (BK21 Program), Plant Molecular Biology and Biotechnology Research Center (PMBBRC), Gyeongsang National University, Jinju 52828, Republic of Korea

3 Department of Plant Bioscience, Life and Industry Convergence Research Institute, Pusan National University, Miryang 627-706, Republic of Korea

4 Life and Industry Convergence Research Institute, Pusan National University, Miryang 50463, Republic of Korea

5 Cold Spring Harbor Laboratory, Cold Spring Harbor, New York, NY, USA
(Yang et al. 2017). This highest productivity of maize among cereal crops has been achieved through prolonged historical human efforts, called domestication, and advances in modern agricultural technology. Maize was domesticated starting 10,000 years ago in Mexico (Harlan 1992; Wang et al. 1999), and has shown remarkable changes in plant architecture from its ancestor, teosinte (Zea mays ssp. Parviglumis) (Doebley 2004; Benz 2001; Doebley and Stec 1993). Teosinte produces many branches and tillers; however, domesticated modern maize generally produces few tillers or branches, and large ears, the female inflorescences. The transformation of the ear is especially mysterious, compared to other crops (Doebley 2004). How could this incredible domestication occur in maize? The first possibility is that the maize genome has a variety of active transposons ( $\mathrm{Mc}$ 1950; Schnable et al. 2009) that promote spontaneous and frequent mutations, leading to transformations. The second possibility is that maize is a typical monoecious plant, indicating that it cross-pollinates. During domestication, many useful traits may have appeared and accumulated (Fu et al. 2002; Brunner et al. 2005). The natural cross-pollination could facilitate easier domestication from teosinte (Yang et al. 2017; van Heerwaarden et al. 2011; Piperno et al. 2009). As a result, two rows of kernels on teosinte ears have been domesticated to produce eight to 20 rows on the ears in maize (Doebley 2004). This remarkable increase in 
the number of kernels per ear is an outstanding feature of domesticated maize.

Many maize mutants defective in shoot apical meristem (SAM) have been selected to investigate and enhance this feature. Interestingly, mutants with dramatically enlarged inflorescence meristems (IMs) showed only a slight increase in the size of vegetative SAMs (Taguchi-Shiobara et al. 2001; Bommert et al. 2013a; Je et al. 2016, 2018), suggesting that the maize genome evolved to promote development of IMs rather than vegetative SAMs during domestication. This intense selection for larger inflorescences has made maize one of the best model crops for studying functional genetics in IM development and offers a great opportunity to identify useful genes for application in yield improvement. A number of mutants with defects in IM, such as those with fasciated ears, have been studied in maize. However, strong fasciated ear mutants do not improve productivity, due to a stunted ear, even though they increase kernel row number (KRN) (Bommert et al. 2013b; Je et al. 2016). To overcome this, maize targeting-induced local lesions in genomes (TILLING) lines with targeted EMS (ethyl methane sulfonate) mutagenesis (Bommert et al. 2013b; Till et al. 2004; Je et al. 2016) were used to isolate weak alleles with moderate IM phenotypes. Compared with strong fasciation mutants, mildly fasciated ear mutants show more potential to improve yield (Bommert et al. 2013b; Je et al. 2016). The TILLING or targeted EMS mutagenesis requires a lot of time and effort. Recent CRISPR/Cas gene-editing techniques make the identification of weak alleles much easier and faster (Shelake et al. 2019; Jinek et al. 2012; Liu et al. 2021b). As the CRISPR/Cas system continues to evolve, it could enable more delicate control over the IM by targeting single bases for editing (Komor et al. 2016; Gaudelli et al. 2017; Shelake et al. 2019; Liu et al. 2021b).

A deep understanding of the genetics underlying development of IMs is crucial for the synergistic application of recent genomic and technological advances in improving crop yields. In this review, we will discuss the maize inflorescence architecture and highlight the various patterns of fasciation to answer this question.

\section{Sex Determination in Maize Inflorescences}

Maize separates male and female flowers into different inflorescences on the same plant (Figs. 1,2), termed monoecious. In the vegetative stage, maize SAMs continuously initiate lateral organs including leaves and axillary buds. After the transition to flowering, the SAM terminates with the production of the male inflorescence, or tassel (Bennetzen and Hake 2009). Interestingly, if the main stalk of maize is broken or removed during the seedling stage, a tiller will replace the broken main stalk. However, the tiller often grows without developing axillary ears, and terminates with the production of a feminized inflorescence, instead of a tassel. The tassel produces several branch meristems (BMs) (Fig. 1A) (Tanaka et al. 2013), whereas axillary buds gives rise to ears, which lack BMs (Fig. 1B). However, three classical mutants,
Fig. 1 Masculinization of the tassel, the male inflorescence in maize. A-I Scanning electron microscopy images (SEMs) of maize tassel development. A Immature tassel produces BMs and regular phyllotaxy of SPMs in the axils of suppressed bracts (SB). B SPMs divide into two SMs. C, D SMs form two glume (GL) primordia and give rise to two FMs, the upper (UFM) and lower (LFM). E, F The UFM forms floral organ primordia. G-I Removal of the GL reveals the LFM that forms floral organ primordia. J A mature male spikelet has two florets. K Schematic representation of reproductive meristem transition in tassel (left) and masculinization of spikelet (right). L, lemma; P, palea; ST, stamen; PI, pistil. Scale bars: $100 \mu \mathrm{m}$
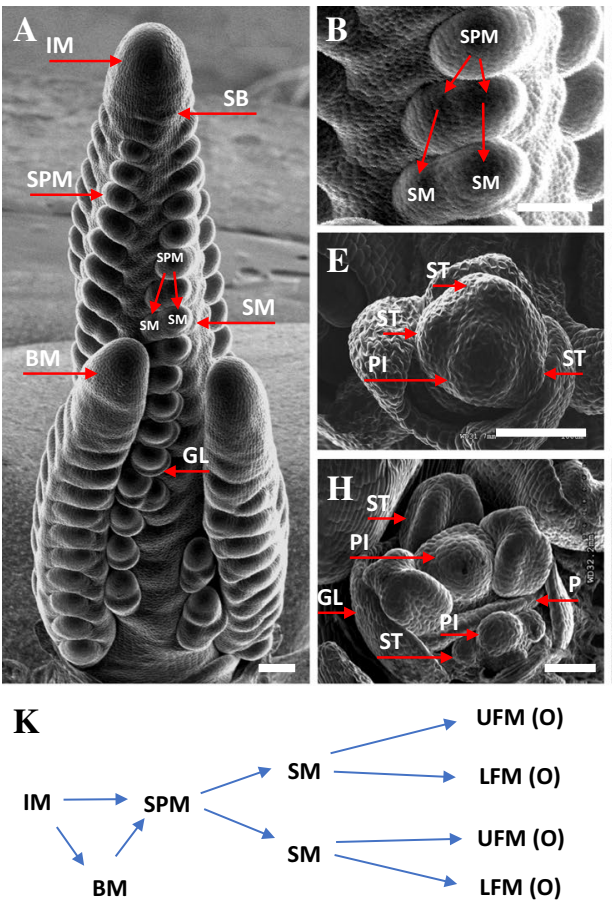
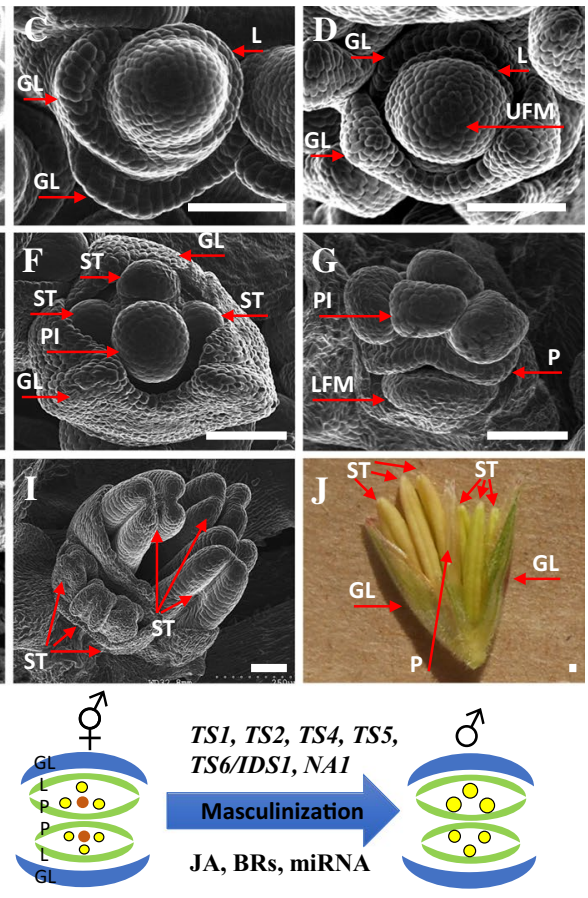

ST (O) PI (o)

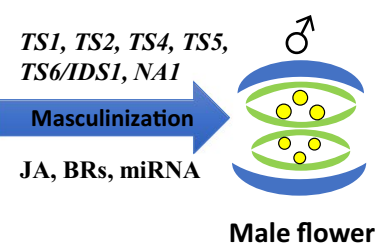



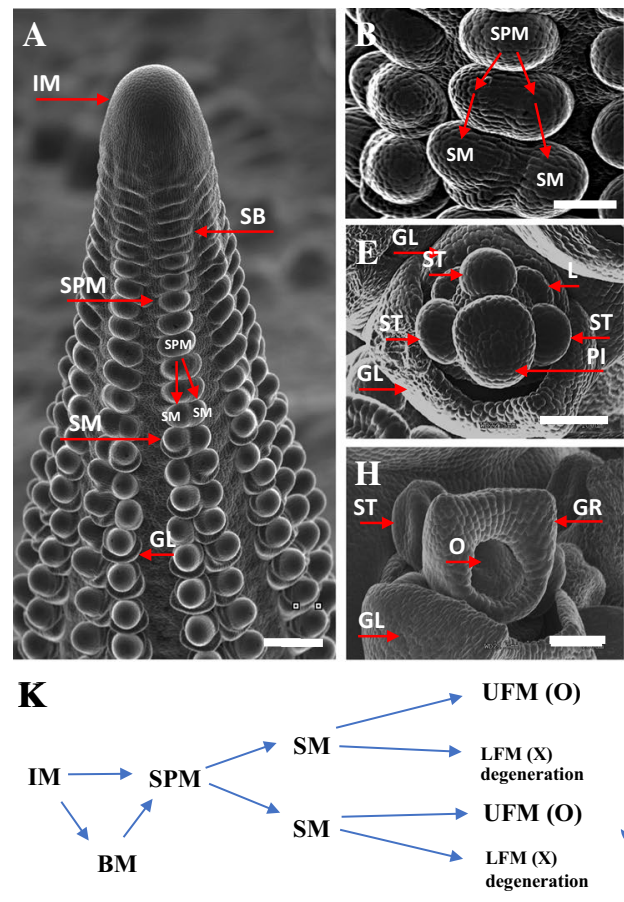

ST (0), PI (o)

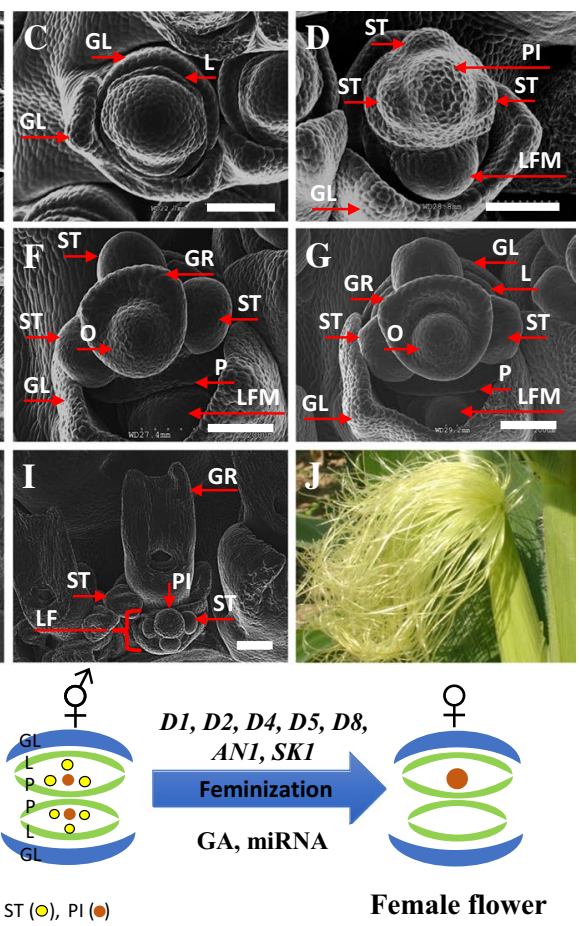

silk. I Removal of the GL reveals the LFM, which also forms floral organ primordia but aborts early in development. J A clump of silks grows from the tip of the ear. $\mathbf{K}$ Schematic representation of reproductive meristem transition in ear (left) and feminization of spikelet (right). L, lemma; P, palea; ST, stamen; PI, pistil; O, ovule. Scale bars: $100 \mu \mathrm{m}$

exogenous jasmonic acid (JA) application, suggesting that JA is involved in masculinization functions of TS1 and TS2 (DeLong et al. 1993; Acosta et al. 2009). The dominant $T s 5$ mutant overexpresses Zea mays ( $\mathrm{Zm}$ ) CYP94B1, and develops a tasselseed phenotype through affecting JA catabolism (Wang et al. 2020; Lunde et al. 2019). In contrast, TS4 encodes a microRNA that controls sex determination by targeting TS6/indeterminate spikeletl (IDS1), which encodes an APETALA2-like transcription factor (Chuck et al. 1998, 2007b). The maize brassinosteroid (BR) biosynthetic mutant, nana plantl (nal) encodes a DET2 homolog, and also has a tasselseed phenotype (Hartwig et al. 2011). Taken together, male sex determinants are involved in the actions of miRNAs and BR and JA hormones (Fig. 1K).

Like the tassel IM, the ear IM initiates SPMs (Fig. 2A), which give rise to a pair of SMs and the SMs subsequently produce two FMs (Fig. 2B). The two FMs initiate floral organ primordia (Fig. 2D-I). However, only the pistil of the upper (primary) floret matures, and all floral organs in the lower (secondary) floret abort (Fig. 2I-K). As a final outcome, each SPM in the ear produces two fertile florets (Fig. 2K). During floral development, the upper peripheral cells of the carpel primordia are recruited to form the

$D R O G E N A S E$ respectively. These mutants are rescued by 
gynoecial ridge that extends into a very long stigma, the pollen-attracting silk (Fig. 2F-J). Degeneration of male organs in the ear is under control of female sex determinants, or feminizing genes (Fig. 2K). These genes were identified as $d$ warf (d) mutants, $d 1, d 2, d 3, d 5, D 8$, and anther earl (anl), which develop perfect flowers without stamen abortion in the upper ear florets (Dellaporta and Calderon-Urrea 1994). These mutations encode genes involved in gibberellin (GA) biosynthesis or signaling (Andersen et al. 2005; Dellaporta and Calderon-Urrea 1994; Bensen et al. 1995). SILKLESS1 (SK1), which encodes a miRNA targeting TS2, acts as a pistil protector (Malcomber and Kellogg 2006; Parkinson et al. 2007). These findings suggest that female sex determinants function in actions of miRNA and GA.

\section{Maize Domestication, Focusing on Inflorescence Architecture}

Domestication of crops involves numerous changes in plant morphology and is achieved through selection of mutations and accumulation of beneficial traits. The monoecy of maize could facilitate the accumulation of many agricultural traits by easy natural outcrossing (Dellaporta and CalderonUrrea 1994). The various active transposons in the maize genome also promote spontaneous mutations that affect gene expression or function (Mc 1950; Schnable et al. 2009). In fact, $\sim 85 \%$ of the maize genome is made up of transposon elements (TEs) (Schnable et al. 2009). For example, one of the most important traits of domestication arose through the activity of a TE. A hopscotch retrotransposon inserted approximately $58 \mathrm{~kb}$ upstream of the teosinte branchedl (tbl) gene (Studer et al. 2011; Clark et al. 2006), results in overexpression of this gene in domesticated maize. $T B 1$ encodes a TB1-CYCLOIDEA-PROLIFERATING CELL FACTOR (TCP) transcription factor that acts as a repressor of axillary bud growth and enables the formation of female inflorescences (Doebley et al. 1997). TB also controls many other domestication genes (Dong et al. 2019), for example, it positively regulates GRASSY TILLERSI (GTI), which encodes a homeodomain-leucine zipper (HD-ZIP) transcription factor that represses tillering and ear prolificacy (Wills et al. 2013; Whipple et al. 2011). These domestication traits increase the apical dominance and concentrate the resources in the main stem of the plant, contributing to increase in size of the inflorescences (Doebley et al. 1997; Wills et al. 2013). TB1 also directly targets teosinte glume architecturel (tgal) and tassels replace upper earsl (trul) by binding to the promoters of these genes (Studer et al. 2017; Dong et al. 2017). Single amino acid change in tgal, which encodes a SQUAMOSA PROMOTER BINDING PROTEIN (SBP) transcription factor, exposes the kernel by softening and reduction of the glumes (Wang et al. 2005,
2015). trul encodes a BTB/POZ ankyrin repeat protein, and the mutants are highly branched with long axillary branches tipped by tassels instead of ears (Dong et al. 2017, 2019), suggesting that $T R U 1$ also functions as a sex determinant downstream of $T B 1$. These effects of $t b 1$ on phenotype vary with genetic background (Doebley et al. 1995). enhancer of tb1.2 (etb1.2) maps to a YABBY transcription factor ZmYAB2.1, also called Zmshattering1-1 (Zmsh1-1), which is expressed in a narrow band of cells subtending the spikelet pair, the future abscission zone (Yang et al. 2016; Lin et al. 2012). $t b 1$ acts as a repressor of $Z m Y A B 2.1$, reducing seed shattering, also called known as non-disarticulation (Stitzer and Ross-Ibarra 2018). The MADS-box transcription factor Zea agamous-likel (zagll) is also involved in seed shattering (Weber et al. 2008), suggesting that this trait is associated with various loci. Although domestication traits related to axillary branching/tiller and growth of glumes have been identified, some IM architecture traits, such as maturation of paired spikelets and inflorescence shift in phyllotaxy from alternating pattern in teosinte with a two-ranked ear to whorled pattern in maize with more than four ranked ear, remain unclear (Stitzer and Ross-Ibarra 2018). Teosinte develops only single mature spikelets, whereas maize has paired spikelets, and this variation is associated with variants on chromosomes 1 and 3 (Doebley and Stec 1991, 1993). Zea floricaula/leafy2 (zfl2) is a candidate locus for inflorescence phyllotaxy differences between maize and teosinte, and shows associations with the ear rank trait in maizeteosinte hybrid populations. An additional QTL, zfll, may alter the effect of $z f 2$ (Bomblies and Doebley 2006; Briggs et al. 2007), however, $z f l ; z$ fl2 double mutants have a normal whorled pattern of axillary meristems initiation (Bomblies and Doebley 2006; Bomblies et al. 2003), suggesting that z fl2 itself was not selected, but a linked gene acting through z $f l 2$ was selected during domestication (Bomblies and Doebley 2006). Although the genetic basis of the shift in inflorescence phyllotaxy from alternating to a whorled pattern remains unclear, many enlarged IM mutants are associated with an increase in ear rank (Taguchi-Shiobara et al. 2001; Bommert et al. 2013b, 2005; Je et al. 2016).

\section{Maize Produces Inflorescences with Dome-Shaped Apical Meristems}

Vegetative SAMs in maize form axillary organs in an alternate pattern, whereas after transition to flowering, IMs form multiple axillary organs in a whorled pattern (Giulini et al. 2004; Jackson and Hake 1999; Yang et al. 2015; Gallavotti et al. 2008). During the vegetative to reproductive transition, the diameter of the dome-shaped SAM increases approximately 1.5- to 2-fold in the B73 inbred line (Fig. 3A-C) (Bommert et al. 2013a, 2013b; Je et al. 2016; Leiboff et al. 


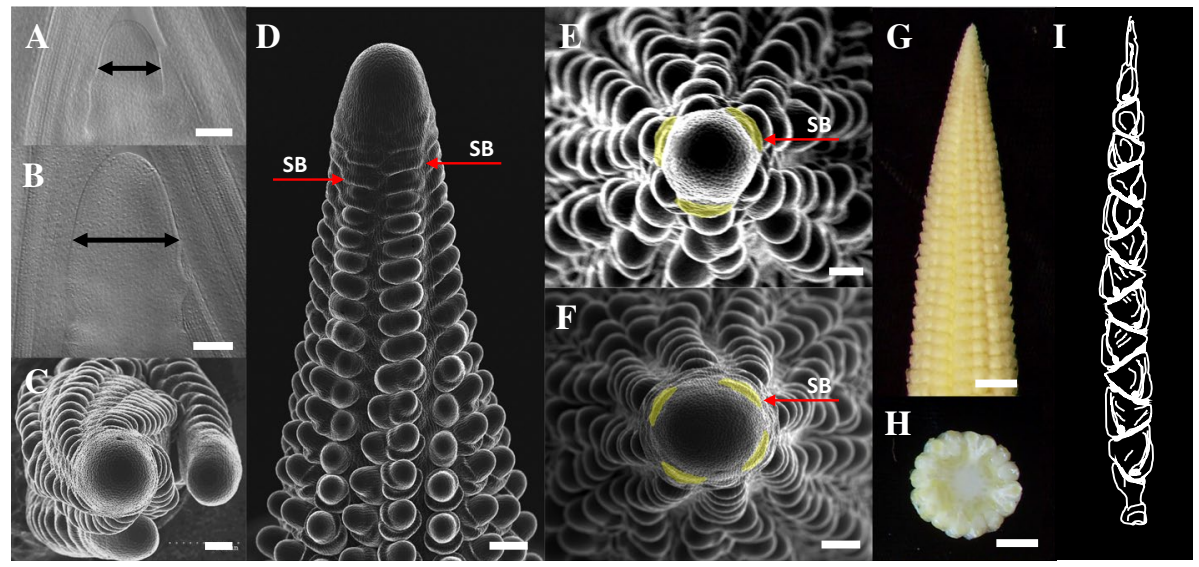

Fig. 3 Wild-type inflorescences with dome-shaped apices. A, B Cleared images of vegetative SAM and tassel IM from wild type. C-F SEMs of IMs from wild type. C, D Top view of a tassel IM and side view of ear IM shows the dome-shaped apex. E, F Top views of ear IMs show the whorled pattern of axillary organ initiation. The suppressed bracts are shaded in yellow, and alternate with adjacent ones. Red arrows indicate suppressed bracts (SBs). G, H Side and cross-section images of immature ears show single-tipped apex and whorled pattern of spikelets. I Diagrammatic illustration of a teosinte ear shows an alternate pattern of kernel rows. Scale bars: $100 \mu \mathrm{m}$ in $\mathbf{A}-\mathbf{F} ; 1 \mathrm{~cm}$ in $\mathbf{G}, \mathbf{H}$

communication system in the SAM is the CLAVATAWUSCHEL (CLV-WUS) negative feedback circuit (Brand et al. 2000; Schoof et al. 2000; Stahl and Simon 2010). CLV signaling pathway is initiated in the CZ by secretion of the CLV3 peptide signal, which is recognized by leucine-rich repeat receptor-like kinase (LRR-RLK) CLV1 (Clark et al. 1997; Fletcher et al. 1999; Jeong et al. 1999). CLV signaling restricts WUS expression to the OC (Brand et al. 2000; Schoof et al. 2000). In turn, the homeodomain transcription factor WUS activates stem cell fate non-cell-autonomously to directly promote CLV3 expression (Daum et al. 2014; Yadav et al. 2011). This CLV-WUS negative feedback signaling was first identified in Arabidopsis, but is also widely conserved in grasses (Somssich et al. 2016). In maize, THICK TASSEL DWARF1 (TDI) and FASCIATED EAR2 (FEA2) encode receptor-like proteins orthologous to CLVI and $C L V 2$, respectively, and regulate the size of the tassel and ear IM (Bommert et al. 2005; Taguchi-Shiobara et al. 2001). FEA2 is broadly expressed in the SAM, similar to CLV2 in Arabidopsis (Jeong et al. 1999; Taguchi-Shiobara et al. 2001), suggesting that the function of $C L V 2 / F E A 2$ is conserved in maize. However, unlike CLVI (Clark et al. 1997), TDI is expressed in the PZ of vegetative SAMs and in the outermost layers of the IMs (Bommert et al. 2005), suggesting that $T D 1$ functions have diversified in maize. Two WUS orthologs in maize, ZmWUS1 and ZmWUS2 were identified by phylogenetic analysis (Nardmann and Werr 2006). ZmWUS1 expression is very weak in the vegetative SAM (Nardmann and Werr 2006), but is detected clearly in the OC of the late vegetative SAM (Je et al. 2016), suggesting that the function of ZmWUS1 is conserved in maize. Maize CLV3/EMBRYO-SURROUNDING REGION7 (ZmCLE7), a 
CLV3 ortholog identified by phylogenetic analysis in maize, is expressed in the L1 layer in IMs and in the CZ of SMs (Chen et al. 2021), and functions as a negative regulator of the meristem (Je et al. 2016). A CRISPR-Cas9 mutant (Zmc$\left.l e 7^{C R}\right)$ and weak promoter alleles $\mathrm{Zmcle}{ }^{7^{C R-p r o}}$ have enlarged IMs (Rodriguez-Leal et al. 2019; Liu et al. 2021a). ZmCLE7 peptide treatment inhibits SAM growth (Je et al. 2016), and triarabinosylated ZmCLE7 peptide is more potent (Je et al. 2018; Lee et al. 2020). ZmCLE1E5 is a related CLE gene that is upregulated in $\mathrm{Zmcle} 7$ mutants, and also expressed in the tips of IMs and in the CZ of SMs (Liu et al. 2021a). Zmcle1e5 mutants enlarge the size of IMs but do not form fasciated ears, though they enhance the fasciation of Zmcle 7 (Liu et al. 2021a). The signaling pathways between CLV and WUS are not clear in maize, but downstream interacting components of FEA2/CLV2 have been identified. COMPACT PLANT2 (CT2), encoding a heterotrimeric $\mathrm{G}$ protein alpha subunit (Bommert et al. 2013a) overlaps in expression with ZmCLE7 in the L1 layer of the IM. Consistent with this, CT2 interacts with FEA2 and suppresses SAM growth through ZmCLE7 signaling (Bommert et al. 2013a; Je et al. 2018). Maize also encodes three non-canonical G alpha subunits, extra-large GTP binding proteins ( $Z m X L G 1$, $Z m X L G 3 a$, and $Z m X L G 3 b$ ), which function redundantly with CT2 in controlling SAM development (Wu et al. 2018a). Interestingly, all Zmxlg triple mutant is seedling lethal due to over-activation of the immune system (Wu et al. 2018a). Maize $G$ protein beta subunit genel ( $\mathrm{ZmG} \beta 1$ ) also functions downstream of FEA2 (Wu et al. 2020). The $Z m g \beta 1^{C R}$ knockout mutant also causes seedling lethality, whereas a weak allele $\mathrm{Zmg} \beta 1^{D 277 N}$ has enlarged IMs and fasciated ears (Wu et al. 2020). ZmCORYNE (CRN) encodes a transmembrane pseudokinase, and also interacts with FEA2, as in Arabidopsis, and inhibits SAM growth through maize FON2-LIKE CLE PROTEINI ( $\mathrm{ZmFCP1)} \mathrm{signaling} \mathrm{(Muller} \mathrm{et} \mathrm{al.} \mathrm{2008;}$ Je et al. 2018). However, CT2 and ZmCRN do not interact with each other, even though FEA2 interacts individually with CT2 or ZmCRN (Je et al. 2018), suggesting that the specificity of FEA2 for different signals is achieved by specific downstream effectors. In fact, FEA2/CLV2 appears to transduce several CLEs signals (Fiers et al. 2005; Meng and Feldman 2010; Hazak et al. 2017) and interacts with various LRR-RLPs in multiple roles (Somssich et al. 2016), suggesting that CLV2/FEA2 is a hub of CLE signaling pathways. However, CLV2/FEA2 does not directly interact with CLE peptides (Somssich et al. 2016; Shinohara and Matsubayashi 2015), indicating that they require unknown co-receptors to perceive CLE peptide signals. The expression of FEA2 is not restricted to the SAM (Taguchi-Shiobara et al. 2001), suggesting that CLV2/FEA2 play multiple roles. CLV2 also appears to be involved in biotic interactions (Replogle et al. 2011; Hanemian et al. 2016) as well as autoimmune signaling (Wu et al. 2020, 2018a).
Given that canonical CLV-WUS signaling pathway mostly involves communication between $\mathrm{CZ}$ and $\mathrm{OC}$ domains within the SAM, it does not explain the balance between stem cell proliferation and ongoing cellular differentiation in the PZ for lateral organ formation (Nardmann et al. 2016; Strable and Scanlon 2016). Feedback signals from organ primordia to the stem cell niche have been proposed to compensate for the defects of communication between stem cell niche and the differentiated descendants (Goldshmidt et al. 2008). FASCIATED EAR3 (FEA3) in maize encodes an LRR receptor-like protein and negatively regulates SAM growth (Je et al. 2016), like CLV signaling. However, FEA3 is expressed in the OC and RZ. fea 3 mutants do not respond to ZmCLE7 peptide, but do respond to ZmFCP1, which is expressed in the $\mathrm{PZ}$ and leaf primordia. Interestingly, FEA3$Z m F C P 1$ signaling restricts $Z m W U S 1$ expression to the $\mathrm{OC}$ by excluding it from the RZ (Je et al. 2016), suggesting that FEA3-ZmFCP1 signaling is involved in communication between differentiated descendants of stem cells and the stem cell niche.

\section{Transcriptional Regulation}

Recently, dominant Barren inflorescence3 (Bif3) mutants were found to harbor a tandem duplicated copy of ZmWUSI, producing a ring-like pattern of $Z m W U S 1$ overexpression in the IM due to a novel chimeric promoter, and enlarged SAM and IM (Chen et al. 2021). However, the Bif3 ring-like pattern of ZmWUS1 expression in IM disappeared in the fea 3 mutant background (Chen et al. 2021), indicating this pattern is related to inhibition by FEA3 in the RZ. Interestingly, the enlarged IMs of Bif3 mutants do not produce typical fasciated ears, but rather small, ball-like ears with few SMs (Chen et al. 2021), suggesting that ZmWUS1 overexpression inhibits the differentiation of axillary organs. Like ZmWUS1, the homeodomain transcription factor KNOTTED1 (KN1) acts non-cell-autonomously to activate meristematic fate (Jackson et al. 1994; Lucas et al. 1995; Kim et al. 2005; Song et al. 2020), as knl loss-of-function mutants exhibit smaller SAMs (Kerstetter et al. 1997; Vollbrecht et al. 2000). $Y A B B Y$ transcription factors DROOPING LEAF1 (DRL1) and $D R L 2$, which are exclusively expressed in leaf primordia, also appear to promote stem cell fate, as the $d r l 1 ; d r l 2$ double mutants have smaller SAMs (Strable et al. 2017), suggesting that DRL1 and DRL2 are also involved in communication between SAMs and the differentiated descendants of stem cells. However, DRL1 and DRL2 seem to be involved in positive feedback signaling. Consistent with this speculation, duplicate copies of two transcription factor genes, MADS-box gene Zmm8 and YABBY gene DRL2, at the Fascicled earl (Fasl) locus, are ectopically overexpressed in the CZ of the IM (Du et al. 2021), leading to an enlarged IM. In addition to these positive stem cell 
regulators, the $b Z I P$ transcription factor $F E A 4$ is a negative stem cell regulator and a PERIANTHIA ortholog in maize (Pautler et al. 2015). FEA4 is expressed in the PZ of the vegetative SAM and throughout the entire IM, and fea 4 mutants exhibit enlarged vegetative SAMs and fasciated IMs. FEA4 interacts with the redox protein MALE STERILE CONVERTED ANTHER1 (MSCA1)/ABPHYL2 (Yang et al., 2015), suggesting that it promotes lateral organ differentiation in the PZ of the SAM. SQUAMOSA PROMOTER BINDING (SBP)-box transcription factor genes unbranched2 (ub2) and $u b 3$ are expressed in the meristem PZ to control inflorescence development (Du et al. 2020; Chuck et al. 2014). These transcription factors are targeted by miRNA156 (Chuck et al. 2010; Wu and Poethig 2006). Two tandem microRNA156 (miR156) are overexpressed in the IM and the lateral organs in $\mathrm{Cg} I$ mutants, which produce fasciated tassels (Chuck et al. 2007a). miRNA biogenesis requires the RNA endonuclease DICER-LIKE1 (Kurihara and Watanabe 2004). In maize, FUZZY TASSEL (FZT) encodes a DICER-LIKE 1 homolog and mutants have inflorescence defects including IM fasciation and severely reduced plant height and shorter, narrower leaves, due to reduced level of miRNAs associated with meristem determinacy, phase change and leaf polarity (Thompson et al. 2014). Similar phenotypes are found in mutants of the transcriptional coactivator grf-interacting factorl (gifl), which is expressed in leaf primordia, PZ, and RZ of the SAM and IM, but not in the CZ (Zhang et al. 2018; Kim and Kende 2004). Most of the mutants in transcriptional regulation genes also have strong defects in tassel development.

\section{Conclusions and Perspectives}

Fasciation patterns are very important for genetic analysis as well as improving crop yields (Fig. 4A-F). However, depending on genetic background or environment, these patterns can be modified. For example, cooler and lower light conditions alleviate fasciation phenotype, as do some genetic backgrounds with smaller IMs, such as Mo17 (Bommert et al. 2013b). Fasciation phenotypes can also be synergistically enhanced in some genetic backgrounds (Yu et al. 2008), providing an opportunity to identify further genetic components. Some weaker mutants have mild flattened IMs without fasciation, whereas stronger mutants exhibit specific patterns of fasciation, such as line or ring fasciation or even IM bifurcation (Fig. 4B-F). This common phenomenon and recent gene-editing techniques open the door to a potential that any mutant with fasciation can help improve crop yields.

However, we are faced with some interesting questions to address.

Why cannot strong alleles be used to improve yield?
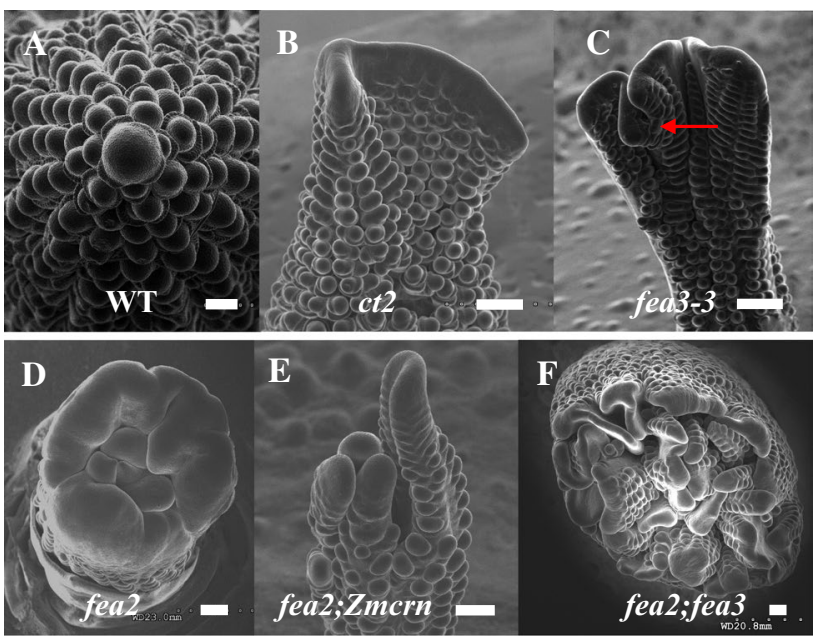

Fig. 4 Strong mutants exhibit specific patterns of fasciation. A Wildtype ear IM shows a dome-shaped apex. B $c t 2$ shows the typical ridge-like line pattern of IM. C IM bifurcation often occurs in the line pattern of ear. Red arrow indicates IM bifurcation. D Ring pattern of IM is often observed in fea 2 mutants. $\mathbf{E}$ The ring pattern of the IM often gives rise to the radial bifurcation of the IM. F Synergistically enhanced fasciation of fea2;fea3 double mutant exhibits a highly enlarged ring pattern of IM with many small ears. Scale bars: $200 \mu \mathrm{m}$

Most strong fasciation mutants with extreme KRN increases have stunted ears with poor yield. To address this issue, weak alleles have been used (Bommert et al. 2013b; Je et al. 2016; Liu et al. 2021a). Why strong fasciation mutations reduce ear length has not been clearly studied. It is speculated that the limited amount of nutrients provided by the source organs may be key signal controlling ear development. In contrast, strong fasciation in tomatoes can increase the size of fruit with increased locule numbers (RodriguezLeal et al. 2017), suggesting that strong fasciation can be very useful for other species.

Can IM regulators promote source organ development?

For yield improvement, sink organ improvement alone is meaningless without joint improvement of photosynthetic source capacity. A weak allele of $f e a 3$ increased overall yield, suggesting that $F E A 3-F C P 1$ signaling impacts sink-source relationships (Je et al. 2016; Kitagawa and Jackson 2019). ZmFCPl overexpression shows has a negative effect on seedling growth, suggesting this gene controls vegetative development and SAM size regulation. $c t 2$ mutants also have defects in leaf development (Bommert et al. 2013a). However, the functions of ZmFCP1 and ZmCLE7 in vegetative growth have not been carefully dissected. In addition, the transcriptional IM regulators, $C g 1, f z t$, gifl, and fea 4 also have vegetative growth defects, suggesting that the growth balance between sink and source organ development may involve IM regulators. Therefore, a better understanding of the function of IM regulators in sink-source balance in plant development may lead to higher yield improvements. 
Which players regulate IM bifurcation?

Bifurcation and branching of IMs (Fig. 4C, E) are important traits for improving plant yields. Patterns of fasciation vary depending on the pathway. Generally, Zmcle7-related mutants show a ridge or ring fasciation (Fig. 4B, D), whereas Zmfcpl-related mutants often have ear bifurcation (Fig. 4C, F). This trend appears to be conserved in Arabidopsis, as $\operatorname{clv} 1, \operatorname{clv} 2$, and $\operatorname{clv} 3$ show little IM bifurcation (*****Clark et al. 1993, 1995, 1997; Kayes and Clark 1998; Jeong et al. 1999; Fletcher et al. 1999), whereas Atfea3 mutants develop reiterative IM bifurcation (Je et al. 2016). A model of Fas 1 action suggests that misexpression of $\mathrm{Zmm} 8$ and $d r l 2$ in the $\mathrm{CZ}$ of the IM suppresses its meristematic activity and promotes meristematic activity in the PZ, resulting in repeatedly bifurcated inflorescences. Consistently, IM bifurcation appears in mutants of fea3, fea4, Zmcrn, ub2;ub3, gif1, and $t d l$, and all these genes are expressed in the PZ or the RZ of vegetative SAMs, but not in from the CZ, suggesting that these genes also promote meristematic activity of the PZ. However, further studies are needed to understand the detailed mechanisms of IM bifurcation.

Are other CLE peptides involved in IM regulation?

Among 49 CLE genes in maize, only ZmCLE7, ZmFCP1, and $Z m C L E 1 e 5$ have been characterized. Zmcle 7 and Zmfcpl mutants develop fasciated ears, and Zmcle le 5 enhances the fasciation phenotype of Zmcle7 (Liu et al. 2021a). However, the others remain uncharacterized, even though many are expressed in shoot tissues (Goad et al. 2017). In addition, other peptides classes may be involved in IM regulation.

How to explain the mysterious ear transformation during domestication?

Many domestication-associated genes in maize have been identified and described with respect to improved traits such as lack of shattering, reduction of tillering and lateral branching, and reduction of glumes and cupules (Dong et al. 2019; Stitzer and Ross-Ibarra 2018). However, a clear explanation of the mysterious transformation of the ear inflorescence phyllotaxy is not yet available. It is believed that domestication of ear rank occurred slowly over $>5000$ years before the present (Benz 2001). Interestingly, the prolificacy domestication trait, related to the number of ears on a shank, is controlled by IM size regulators, including $\mathrm{G}$ protein alpha subunit ct 2 and gifl that suppress axillary ear formation (Urano et al. 2015; Zhang et al. 2018). These observations suggest that fasciation mutants are involved deeply in maize domestication.

Although the genes involved in domestication and inflorescence architecture appear to be conserved in diverse plant species (Dong et al. 2019; Kitagawa and Jackson 2019; Liu et al. 2021b), the ear architecture of maize is unique in grain crops. The further understanding of maize inflorescence architecture could help improve yields in maize and other crops.
Acknowledgements This work was supported by the Basic Science Research Program through the National Research Foundation of Korea (NRF), funded by the Korea government (MSIT) (NRF2018R1D1A1B07047711, NRF-2021R1A4A2001968 and NRF2021R1A2C1095401). Jum-soon Kang was supported by Korea Institute of Planning and Evaluation for Technology in Food, Agriculture and Forestry (IPET) and Korea Smart Farm R\&D Foundation (KosFarm) through Smart Farm Innovation Technology Development Program, funded by Ministry of Agriculture, Food and Rural Affairs (MAFRA) and Ministry of Science and ICT (MSIT), Rural Development Administration (RDA) (421037031SB010 and 421037031HD030). Dave Jackson was supported by NIFA award 201905613 and NSF award IOS-2129189.

Author Contributions DEK, JHJ, YMK, DJ and BIJ designed and wrote the manuscript. YHP, YJL, JSK, YWC, BGS and STK provided scientific discussion. YHP, YJL, JSK, YWC, STK, DJ and BIJ contributed to the conception. All the authors agreed on the contents of the paper and critically evaluated the manuscript.

\section{Declarations}

Conflict of interest The authors declare that they have no competing interests.

Ethics Approval and Consent to Participate This article does not contain any studies with human participants or animals performed by any of the authors.

Consent for Publication All the authors have provided consent for publication.

Open Access This article is licensed under a Creative Commons Attribution 4.0 International License, which permits use, sharing, adaptation, distribution and reproduction in any medium or format, as long as you give appropriate credit to the original author(s) and the source, provide a link to the Creative Commons licence, and indicate if changes were made. The images or other third party material in this article are included in the article's Creative Commons licence, unless indicated otherwise in a credit line to the material. If material is not included in the article's Creative Commons licence and your intended use is not permitted by statutory regulation or exceeds the permitted use, you will need to obtain permission directly from the copyright holder. To view a copy of this licence, visit http://creativecommons.org/licenses/by/4.0/.

\section{References}

Acosta IF, Laparra H, Romero SP, Schmelz E, Hamberg M, Mottinger JP, Moreno MA, Dellaporta SL (2009) tasselseed1 is a lipoxygenase affecting jasmonic acid signaling in sex determination of maize. Science 323(5911):262-265

Andersen JR, Schrag T, Melchinger AE, Zein I, Lubberstedt T (2005) Validation of Dwarf8 polymorphisms associated with flowering time in elite European inbred lines of maize (Zea mays L.). Theor Appl Genet 111(2):206-217

Bennetzen JL, Hake S (2009) Handbook of maize: its biology. Springer, New York

Bensen RJ, Johal GS, Crane VC, Tossberg JT, Schnable PS, Meeley RB, Briggs SP (1995) Cloning and characterization of the maize An1 gene. Plant Cell 7(1):75-84 
Benz BF (2001) Archaeological evidence of teosinte domestication from Guila Naquitz, Oaxaca. Proc Natl Acad Sci USA 98(4):2104-2106

Bomblies K, Doebley JF (2006) Pleiotropic effects of the duplicate maize FLORICAULA/LEAFY genes zfl1 and zfl 2 on traits under selection during maize domestication. Genetics 172(1):519-531

Bomblies K, Wang RL, Ambrose BA, Schmidt RJ, Meeley RB, Doebley J (2003) Duplicate FLORICAULA/LEAFY homologs zfl1 and zfl 2 control inflorescence architecture and flower patterning in maize. Development 130(11):2385-2395

Bommert P, Lunde C, Nardmann J, Vollbrecht E, Running M, Jackson D, Hake S, Werr W (2005) thick tassel dwarf1 encodes a putative maize ortholog of the Arabidopsis CLAVATA1 leucine-rich repeat receptor-like kinase. Development 132(6):1235-1245

Bommert P, Je BI, Goldshmidt A, Jackson D (2013a) The maize Galpha gene COMPACT PLANT2 functions in CLAVATA signalling to control shoot meristem size. Nature 502(7472):555-558

Bommert P, Nagasawa NS, Jackson D (2013b) Quantitative variation in maize kernel row number is controlled by the FASCIATED EAR2 locus. Nat Genet 45(3):334-337

Bortiri E, Chuck G, Vollbrecht E, Rocheford T, Martienssen R, Hake $S$ (2006) ramosa2 encodes a LATERAL ORGAN BOUNDARY domain protein that determines the fate of stem cells in branch meristems of maize. Plant Cell 18(3):574-585

Brand U, Fletcher JC, Hobe M, Meyerowitz EM, Simon R (2000) Dependence of stem cell fate in Arabidopsis on a feedback loop regulated by CLV3 activity. Science 289(5479):617-619

Briggs WH, McMullen MD, Gaut BS, Doebley J (2007) Linkage mapping of domestication loci in a large maize teosinte backcross resource. Genetics 177(3):1915-1928

Brunner S, Fengler K, Morgante M, Tingey S, Rafalski A (2005) Evolution of DNA sequence nonhomologies among maize inbreds. Plant Cell 17(2):343-360

Chen ZL, Li W, Gaines C, Buck A, Galli M, Gallavotti A (2021) Structural variation at the maize WUSCHEL1 locus alters stem cell organization in inflorescences. Nat Commun 12(1):2378

Chuck G, Meeley RB, Hake S (1998) The control of maize spikelet meristem fate by the APETALA2-like gene indeterminate spikelet1. Gene Dev 12(8):1145-1154

Chuck G, Cigan AM, Saeteurn K, Hake S (2007a) The heterochronic maize mutant Corngrass1 results from overexpression of a tandem microRNA. Nat Genet 39(4):544-549

Chuck G, Meeley R, Irish E, Sakai H, Hake S (2007b) The maize tasselseed 4 microRNA controls sex determination and meristem cell fate by targeting Tasselseed6/indeterminate spikelet1. Nat Genet 39(12):1517-1521

Chuck G, Whipple C, Jackson D, Hake S (2010) The maize SBP-box transcription factor encoded by tasselsheath 4 regulates bract development and the establishment of meristem boundaries. Development 137(8):1243-1250

Chuck GS, Brown PJ, Meeley R, Hake S (2014) Maize SBP-box transcription factors unbranched 2 and unbranched 3 affect yield traits by regulating the rate of lateral primordia initiation. Proc Natl Acad Sci USA 111(52):18775-18780

Clark SE, Running MP, Meyerowitz EM (1993) CLAVATA1, a regulator of meristem and flower development in Arabidopsis. Development 119(2):397-418

Clark SE, Running MP, Meyerowitz EM (1995) Clavata3 is a specific regulator of shoot and floral meristem development affecting the same processes as Clavata1. Development 121(7):2057-2067

Clark SE, Williams RW, Meyerowitz EM (1997) The CLAVATA1 gene encodes a putative receptor kinase that controls shoot and floral meristem size in Arabidopsis. Cell 89(4):575-585

Clark RM, Wagler TN, Quijada P, Doebley J (2006) A distant upstream enhancer at the maize domestication gene tb1 has pleiotropic effects on plant and inflorescent architecture. Nat Genet 38(5):594-597

Daum G, Medzihradszky A, Suzaki T, Lohmann JU (2014) A mechanistic framework for noncell autonomous stem cell induction in Arabidopsis. Proc Natl Acad Sci USA 111(40):14619-14624

Dellaporta SL, Calderon-Urrea A (1994) The sex determination process in maize. Science 266(5190):1501-1505

DeLong A, Calderon-Urrea A, Dellaporta SL (1993) Sex determination gene TASSELSEED2 of maize encodes a short-chain alcohol dehydrogenase required for stage-specific floral organ abortion. Cell 74(4):757-768

Doebley J (2004) The genetics of maize evolution. Annu Rev Genet 38:37-59

Doebley J, Stec A (1991) Genetic analysis of the morphological differences between maize and teosinte. Genetics 129(1):285-295

Doebley J, Stec A (1993) Inheritance of the morphological differences between maize and teosinte-comparison of results for $2 \mathrm{~F} 2$ populations. Genetics 134(2):559-570

Doebley J, Stec A, Gustus C (1995) teosinte branched1 and the origin of maize: evidence for epistasis and the evolution of dominance. Genetics 141(1):333-346

Doebley J, Stec A, Hubbard L (1997) The evolution of apical dominance in maize. Nature 386(6624):485-488

Dong ZB, Li W, Unger-Wallace E, Yang JL, Vollbrecht E, Chuck $\mathrm{G}$ (2017) Ideal crop plant architecture is mediated by tassels replace upper ears1, a BTB/POZ ankyrin repeat gene directly targeted by TEOSINTE BRANCHED1. Proc Natl Acad Sci USA 114(41):E8656-E8664

Dong ZB, Alexander M, Chuck G (2019) Understanding grass domestication through maize mutants. Trends Genet 35(2):118-128

Du Y, Liu L, Peng Y, Li M, Li Y, Liu D, Li X, Zhang Z (2020) UNBRANCHED3 expression and inflorescence development is mediated by UNBRANCHED2 and the distal enhancer, KRN4, in maize. Plos Genet 16(4):e1008764

Du Y, Lunde C, Li Y, Jackson D, Hake S, Zhang Z (2021) Gene duplication at the Fascicled ear1 locus controls the fate of inflorescence meristem cells in maize. Proc Natl Acad Sci USA 118(7):e2019218118

Fiers M, Golemiec E, Xu J, van der Geest L, Heidstra R, Stiekema W, Liu CM (2005) The 14-amino acid CLV3, CLE19, and CLE40 peptides trigger consumption of the root meristem in Arabidopsis through a CLAVATA2-dependent pathway. Plant Cell 17(9):2542-2553

Fletcher JC, Brand U, Running MP, Simon R, Meyerowitz EM (1999) Signaling of cell fate decisions by CLAVATA3 in Arabidopsis shoot meristems. Science 283(5409):1911-1914

Fu HH, Zheng ZW, Dooner HK (2002) Recombination rates between adjacent genic and retrotransposon regions in maize vary by 2 orders of magnitude. Proc Natl Acad Sci USA 99(2):1082-1087

Gallavotti A, Yang Y, Schmidt RJ, Jackson D (2008) The relationship between auxin transport and maize branching. Plant Physiol 147(4):1913-1923

Gaudelli NM, Komor AC, Rees HA, Packer MS, Badran AH, Bryson DI, Liu DR (2017) Programmable base editing of AT to GC in genomic DNA without DNA cleavage. Nature 551(7681):464

Giulini A, Wang J, Jackson D (2004) Control of phyllotaxy by the cytokinin-inducible response regulator homologue ABPHYL1. Nature 430(7003): 1031-1034

Goad DM, Zhu C, Kellogg EA (2017) Comprehensive identification and clustering of CLV3/ESR-related (CLE) genes in plants finds groups with potentially shared function. New Phytol 216(2):605-616

Goldshmidt A, Alvarez JP, Bowman JL, Eshed Y (2008) Signals derived from YABBY gene activities in organ primordia regulate growth and partitioning of Arabidopsis shoot apical meristems. Plant Cell 20(5):1217-1230 
Hanemian M, Barlet X, Sorin C, Yadeta KA, Keller H, Favery B, Simon R, Thomma BP, Hartmann C, Crespi M, Marco Y, Tremousaygue D, Deslandes L (2016) Arabidopsis CLAVATA1 and CLAVATA2 receptors contribute to Ralstonia solanacearum pathogenicity through a miR169-dependent pathway. New Phytol 211(2):502-515

Harlan JR (1992) Crops \& man, 2nd edn. American Society of Agronomy: Crop Science Society of America, Madison

Hartwig T, Chuck GS, Fujioka S, Klempien A, Weizbauer R, Potluri DPV, Choe S, Johal GS, Schulz B (2011) Brassinosteroid control of sex determination in maize. Proc Natl Acad Sci USA 108(49):19814-19819

Hazak O, Brandt B, Cattaneo P, Santiago J, Rodriguez-Villalon A, Hothorn M, Hardtke CS (2017) Perception of root-active CLE peptides requires CORYNE function in the phloem vasculature. Embo Rep 18(8):1367-1381

Heidstra R, Sabatini S (2014) Plant and animal stem cells: similar yet different. Nat Rev Mol Cell Biol 15(5):301-312

Jackson D, Hake S (1999) Control of phyllotaxy in maize by the abphyl1 gene. Development 126(2):315-323

Jackson D, Veit B, Hake S (1994) Expression of maize knotted1 related homeobox genes in the shoot apical meristem predicts patterns of morphogenesis in the vegetative shoot. Development 120(2):405-413

Je BI, Gruel J, Lee YK, Bommert P, Arevalo ED, Eveland AL, Wu Q, Goldshmidt A, Meeley R, Bartlett M, Komatsu M, Sakai H, Jonsson H, Jackson D (2016) Signaling from maize organ primordia via FASCIATED EAR3 regulates stem cell proliferation and yield traits. Nat Genet 48(7):785-791

Je BI, Xu F, Wu Q, Liu L, Meeley R, Gallagher JP, Corcilius L, Payne RJ, Bartlett ME, Jackson D (2018) The CLAVATA receptor FASCIATED EAR2 responds to distinct CLE peptides by signaling through two downstream effectors. Elife 7:e35673

Jeong S, Trotochaud AE, Clark SE (1999) The Arabidopsis CLAVATA2 gene encodes a receptor-like protein required for the stability of the CLAVATA1 receptor-like kinase. Plant Cell 11(10):1925-1934

Jinek M, Chylinski K, Fonfara I, Hauer M, Doudna JA, Charpentier E (2012) A Programmable dual-RNA-guided DNA endonuclease in adaptive bacterial immunity. Science 337(6096):816-821

Kayes JM, Clark SE (1998) CLAVATA2, a regulator of meristem and organ development in Arabidopsis. Development 125(19):3843-3851

Kerstetter RA, Laudencia-Chingcuanco D, Smith LG, Hake S (1997) Loss-of-function mutations in the maize homeobox gene, knotted1, are defective in shoot meristem maintenance. Development 124(16):3045-3054

Kim JH, Kende H (2004) A transcriptional coactivator, AtGIF1, is involved in regulating leaf growth and morphology in Arabidopsis. Proc Natl Acad Sci USA 101(36):13374-13379

Kim JY, Rim Y, Wang J, Jackson D (2005) A novel cell-to-cell trafficking assay indicates that the KNOX homeodomain is necessary and sufficient for intercellular protein and mRNA trafficking. Genes Dev 19(7):788-793

Kitagawa M, Jackson D (2019) Control of Meristem Size. Annu Rev Plant Biol 70:269-291

Komor AC, Kim YB, Packer MS, Zuris JA, Liu DR (2016) Programmable editing of a target base in genomic DNA without double-stranded DNA cleavage. Nature 533(7603):420

Kurihara Y, Watanabe Y (2004) Arabidopsis micro-RNA biogenesis through Dicer-like 1 protein functions. Proc Natl Acad Sci USA 101(34):12753-12758

Lee KH, Kwon DH, Song JK, Seo HS (2020) Production mechanisms, structural features and post-translational modifications of plant peptides. J Plant Biol 63:259-265
Leiboff S, Li X, Hu HC, Todt N, Yang J, Li X, Yu X, Muehlbauer GJ, Timmermans MC, Yu J, Schnable PS, Scanlon MJ (2015) Genetic control of morphometric diversity in the maize shoot apical meristem. Nat Commun 6:8974

Leiboff S, DeAllie CK, Scanlon MJ (2016) Modeling the morphometric evolution of the maize shoot apical meristem. Front Plant Sci 7:1651

Lin Z, Li X, Shannon LM, Yeh CT, Wang ML, Bai G, Peng Z, Li J, Trick HN, Clemente TE, Doebley J, Schnable PS, Tuinstra MR, Tesso TT, White F, Yu J (2012) Parallel domestication of the Shattering 1 genes in cereals. Nat Genet 44(6):720-724

Liu L, Gallagher J, Arevalo ED, Chen R, Skopelitis T, Wu Q, Bartlett M, Jackson D (2021a) Enhancing grain-yield-related traits by CRISPR-Cas9 promoter editing of maize CLE genes. Nat Plants 7(3):287-294

Liu L, Lindsay PL, Jackson D (2021b) Next generation cereal crop yield enhancement: from knowledge of inflorescence development to practical engineering by genome editing. Int J Mol Sci 22(10):5167

Lucas WJ, Bouche-Pillon S, Jackson DP, Nguyen L, Baker L, Ding B, Hake S (1995) Selective trafficking of KNOTTED1 homeodomain protein and its mRNA through plasmodesmata. Science 270(5244):1980-1983

Lunde C, Kimberlin A, Leiboff S, Koo AJ, Hake S (2019) Tasselseed5 overexpresses a wound-inducible enzyme, ZmCYP94B1, that affects jasmonate catabolism, sex determination, and plant architecture in maize. Commun Biol 2:114

Malcomber ST, Kellogg EA (2006) Evolution of unisexual flowers in grasses (Poaceae) and the putative sex-determination gene, TASSELSEED2 (TS2). New Phytol 170(4):885-899

Mc CB (1950) The origin and behavior of mutable loci in maize. Proc Natl Acad Sci USA 36(6):344-355

Meng L, Feldman LJ (2010) CLE14/CLE20 peptides may interact with CLAVATA2/CORYNE receptor-like kinases to irreversibly inhibit cell division in the root meristem of Arabidopsis. Planta 232(5):1061-1074

Morrison SJ, Spradling AC (2008) Stem cells and niches: mechanisms that promote stem cell maintenance throughout life. Cell 132(4):598-611

Muller R, Bleckmann A, Simon R (2008) The receptor kinase CORYNE of Arabidopsis transmits the stem cell-limiting signal CLAVATA3 independently of CLAVATA1. Plant Cell 20(4):934-946

Nardmann J, Werr W (2006) The shoot stem cell niche in angiosperms: expression patterns of WUS orthologues in rice and maize imply major modifications in the course of mono- and dicot evolution. Mol Biol Evol 23(12):2492-2504

Nardmann J, Chandler JW, Werr W (2016) Stem cell fate versus differentiation: the missing link. Trends Plant Sci 21(9):725-727

Parkinson SE, Gross SM, Hollick JB (2007) Maize sex determination and abaxial leaf fates are canalized by a factor that maintains repressed epigenetic states. Dev Biol 308(2):462-473

Pautler M, Eveland AL, LaRue T, Yang F, Weeks R, Lunde C, Je BI, Meeley R, Komatsu M, Vollbrecht E, Sakai H, Jackson D (2015) FASCIATED EAR4 encodes a bZIP transcription factor that regulates shoot meristem size in maize. Plant Cell 27(1):104-120

Piperno DR, Ranere AJ, Holst I, Iriarte J, Dickau R (2009) Starch grain and phytolith evidence for early ninth millennium B.P. maize from the Central Balsas River Valley, Mexico. Proc Natl Acad Sci USA 106(13):5019-5024

Replogle A, Wang J, Bleckmann A, Hussey RS, Baum TJ, Sawa S, Davis EL, Wang X, Simon R, Mitchum MG (2011) Nematode CLE signaling in Arabidopsis requires CLAVATA2 and CORYNE. Plant J 65(3):430-440 
Rodriguez-Leal D, Lemmon ZH, Man J, Bartlett ME, Lippman ZB (2017) Engineering quantitative trait variation for crop improvement by genome editing. Cell 171(2):470-480 (e478)

Rodriguez-Leal D, Xu C, Kwon CT, Soyars C, Demesa-Arevalo E, Man J, Liu L, Lemmon ZH, Jones DS, Van Eck J, Jackson DP, Bartlett ME, Nimchuk ZL, Lippman ZB (2019) Evolution of buffering in a genetic circuit controlling plant stem cell proliferation. Nat Genet 51(5):786

Satoh-Nagasawa N, Nagasawa N, Malcomber S, Sakai H, Jackson D (2006) A trehalose metabolic enzyme controls inflorescence architecture in maize. Nature 441(7090):227-230

Schnable PS, Ware D, Fulton RS, Stein JC, Wei F, Pasternak S, Liang C, Zhang J, Fulton L, Graves TA, Minx P, Reily AD, Courtney L, Kruchowski SS, Tomlinson C, Strong C, Delehaunty K, Fronick C, Courtney B, Rock SM, Belter E, Du F, Kim K, Abbott RM, Cotton M, Levy A, Marchetto P, Ochoa K, Jackson SM, Gillam B, Chen W, Yan L, Higginbotham J, Cardenas M, Waligorski J, Applebaum E, Phelps L, Falcone J, Kanchi K, Thane T, Scimone A, Thane N, Henke J, Wang T, Ruppert J, Shah N, Rotter K, Hodges J, Ingenthron E, Cordes M, Kohlberg S, Sgro J, Delgado B, Mead K, Chinwalla A, Leonard S, Crouse K, Collura K, Kudrna D, Currie J, He R, Angelova A, Rajasekar S, Mueller T, Lomeli R, Scara G, Ko A, Delaney K, Wissotski M, Lopez G, Campos D, Braidotti M, Ashley E, Golser W, Kim H, Lee S, Lin J, Dujmic Z, Kim W, Talag J, Zuccolo A, Fan C, Sebastian A, Kramer M, Spiegel L, Nascimento L, Zutavern T, Miller B, Ambroise C, Muller S, Spooner W, Narechania A, Ren L, Wei S, Kumari S, Faga B, Levy MJ, McMahan L, Van Buren P, Vaughn MW, Ying K, Yeh CT, Emrich SJ, Jia Y, Kalyanaraman A, Hsia AP, Barbazuk WB, Baucom RS, Brutnell TP, Carpita NC, Chaparro C, Chia JM, Deragon JM, Estill JC, Fu Y, Jeddeloh JA, Han Y, Lee H, Li P, Lisch DR, Liu S, Liu Z, Nagel DH, McCann MC, SanMiguel P, Myers AM, Nettleton D, Nguyen J, Penning BW, Ponnala L, Schneider KL, Schwartz DC, Sharma A, Soderlund C, Springer NM, Sun Q, Wang H, Waterman M, Westerman R, Wolfgruber TK, Yang L, Yu Y, Zhang L, Zhou S, Zhu Q, Bennetzen JL, Dawe RK, Jiang J, Jiang N, Presting GG, Wessler SR, Aluru S, Martienssen RA, Clifton SW, McCombie WR, Wing RA, Wilson RK (2009) The B73 maize genome: complexity, diversity, and dynamics. Science 326(5956):1112-1115

Schoof H, Lenhard M, Haecker A, Mayer KFX, Jurgens G, Laux T (2000) The stem cell population of Arabidopsis shoot meristems is maintained by a regulatory loop between the CLAVATA and WUSCHEL genes. Cell 100(6):635-644

Shelake RM, Pramanik D, Kim JY (2019) Evolution of plant mutagenesis tools: a shifting paradigm from random to targeted genome editing. Plant Biotechnol Rep 13(5):423-445

Shinohara H, Matsubayashi Y (2015) Reevaluation of the CLV3-receptor interaction in the shoot apical meristem: dissection of the CLV3 signaling pathway from a direct ligand-binding point of view. Plant J 82(2):328-336

Somssich M, Je BI, Simon R, Jackson D (2016) CLAVATAWUSCHEL signaling in the shoot meristem. Development 143(18):3238-3248

Song S, Yun YB, Lee MM (2020) SHOOT MERISTEMLESS is required for the proper internode patterning and the sepal separation in Arabidopsis. J Plant Biol 63:33-42

Stahl Y, Simon R (2010) Plant primary meristems: shared functions and regulatory mechanisms. Curr Opin Plant Biol 13(1):53-58

Stitzer MC, Ross-Ibarra J (2018) Maize domestication and gene interaction. New Phytol 220(2):395-408

Strable J, Scanlon MJ (2016) Meristems take their cues from organ primordia. Nat Genet 48(7):704-705

Strable J, Wallace JG, Unger-Wallace E, Briggs S, Bradbury PJ, Buckler ES, Vollbrecht E (2017) Maize YABBY genes drooping leaf 1 and drooping leaf2 regulate plant architecture. Plant Cell 29(7):1622-1641

Studer A, Zhao Q, Ross-Ibarra J, Doebley J (2011) Identification of a functional transposon insertion in the maize domestication gene tb1. Nat Genet 43(11):1160-1163

Studer AJ, Wang H, Doebley JF (2017) Selection during maize domestication targeted a gene network controlling plant and inflorescence architecture. Genetics 207(2):755-765

Taguchi-Shiobara F, Yuan Z, Hake S, Jackson D (2001) The fasciated ear2 gene encodes a leucine-rich repeat receptor-like protein that regulates shoot meristem proliferation in maize. Gene Dev 15(20):2755-2766

Tanaka W, Pautler M, Jackson D, Hirano HY (2013) Grass meristems II: inflorescence architecture, flower development and meristem fate. Plant Cell Physiol 54(3):313-324

Thompson BE, Basham C, Hammond R, Ding Q, Kakrana A, Lee TF, Simon SA, Meeley R, Meyers BC, Hake S (2014) The dicer-like1 homolog fuzzy tassel is required for the regulation of meristem determinacy in the inflorescence and vegetative growth in maize. Plant Cell 26(12):4702-4717

Till BJ, Reynolds SH, Weil C, Springer N, Burtner C, Young K, Bowers E, Codomo CA, Enns LC, Odden AR, Greene EA, Comai L, Henikoff S (2004) Discovery of induced point mutations in maize genes by TILLING. BMC Plant Biol 4:12

Urano D, Jackson D, Jones AM (2015) A G protein alpha null mutation confers prolificacy potential in maize. J Exp Bot 66(15):4511-4515

van Heerwaarden J, Doebley J, Briggs WH, Glaubitz JC, Goodman MM, de Jesus Sanchez GonzalezRoss-Ibarra JJ (2011) Genetic signals of origin, spread, and introgression in a large sample of maize landraces. Proc Natl Acad Sci USA 108(3):1088-1092

Vollbrecht E, Reiser L, Hake S (2000) Shoot meristem size is dependent on inbred background and presence of the maize homeobox gene, knotted1. Development 127(14):3161-3172

Vollbrecht E, Springer PS, Goh L, BucklerMartienssen ESTR (2005) Architecture of floral branch systems in maize and related grasses. Nature 436(7054):1119-1126

Wang RL, Stec A, Hey J, Lukens L, Doebley J (1999) The limits of selection during maize domestication. Nature 398(6724):236-239

Wang H, Nussbaum-Wagler T, Li BL, Zhao Q, Vigouroux Y, Faller M, Bomblies K, Lukens L, Doebley JF (2005) The origin of the naked grains of maize. Nature 436(7051):714-719

Wang H, Studer AJ, Zhao Q, Meeley R, Doebley JF (2015) Evidence that the origin of naked kernels during maize domestication was caused by a single amino acid substitution in tga1. Genetics 200(3):965

Wang F, Yuan ZJ, Zhao ZW, Li CX, Zhang X, Liang HF, Liu YW, Xu Q, Liu HT (2020) Tasselseed5 encodes a cytochrome C oxidase that functions in sex determination by affecting jasmonate catabolism in maize. J Integr Plant Biol 62(2):247-255

Weber AL, Briggs WH, Rucker J, Baltazar BM, de Jesus S-G, Feng P, Buckler ES, Doebley J (2008) The genetic architecture of complex traits in teosinte (Zea mays ssp. parviglumis): new evidence from association mapping. Genetics 180(2):1221-1232

Whipple CJ, Kebrom TH, Weber AL, Yang F, Hall D, Meeley R, Schmidt R, Doebley J, Brutnell TP, Jackson DP (2011) grassy tillers1 promotes apical dominance in maize and responds to shade signals in the grasses. Proc Natl Acad Sci USA 108(33):E506-E512

Wills DM, Whipple CJ, Takuno S, Kursel LE, Shannon LM, RossIbarra J, Doebley JF (2013) From many, one: genetic control of prolificacy during maize domestication. Plos Genet 9(6):e1003604 
Wu G, Poethig RS (2006) Temporal regulation of shoot development in Arabidopsis thaliana by miR156 and its target SPL3. Development 133(18):3539-3547

Wu Q, Regan M, Furukawa H, Jackson D (2018a) Role of heterotrimeric Galpha proteins in maize development and enhancement of agronomic traits. Plos Genet 14(4):e1007374

Wu Q, Xu F, Jackson D (2018b) All together now, a magical mystery tour of the maize shoot meristem. Curr Opin Plant Biol 45(Pt A):26-35

Wu Q, Xu F, Liu L, Char SN, Ding Y, Je BI, Schmelz E, Yang B, Jackson D (2020) The maize heterotrimeric G protein beta subunit controls shoot meristem development and immune responses. Proc Natl Acad Sci USA 117(3):1799-1805

Yadav RK, Perales M, Gruel J, Girke T, Jonsson H, Reddy GV (2011) WUSCHEL protein movement mediates stem cell homeostasis in the Arabidopsis shoot apex. Genes Dev 25(19):2025-2030

Yang F, Bui HT, Pautler M, Llaca V, Johnston R, Lee BH, Kolbe A, Sakai H, Jackson D (2015) A maize glutaredoxin gene, abphyl2, regulates shoot meristem size and phyllotaxy. Plant Cell 27(1):121-131

Yang CJ, Kursel LE, Studer AJ, Bartlett ME, Whipple CJ, Doebley JF (2016) A gene for genetic background in Zea mays: fine-mapping enhancer of teosinte branched1.2 to a YABBY class transcription factor. Genetics 204(4):1573-1585

Yang N, Xu XW, Wang RR, Peng WL, Cai L, Song JM, Li W, Luo X, Niu L, Wang Y, Jin M, Chen L, Luo J, Deng M, Wang L, Pan Q, Liu F, Jackson D, Yang X, Chen LL, Yan J (2017) Contributions of Zea mays subspecies mexicana haplotypes to modern maize. Nat Commun 8(1):1874.

Yu J, Holland JB, McMullen MD, Buckler ES (2008) Genetic design and statistical power of nested association mapping in maize. Genetics 178(1):539-551

Zhang D, Sun W, Singh R, Zheng Y, Cao Z, Li M, Lunde C, Hake S, Zhang Z (2018) GRF-interacting factor1 regulates shoot architecture and meristem determinacy in maize. Plant Cell 30(2):360-374 